\title{
Psychological Preparation of Children for Surgery: Awareness Survey Targeting Medical Professionals
}

\author{
Naomi Matsumori \\ Department of Nursing, Faculty of Health and Welfare, Prefectural University of Hiroshima, Hiroshima, Japan \\ Email: matumori@pu-hiroshima.ac.jp
}

Received 17 April 2014; revised 26 May 2014; accepted 16 June 2014

Copyright (C) 2014 by author and Scientific Research Publishing Inc. This work is licensed under the Creative Commons Attribution International License (CC BY). http://creativecommons.org/licenses/by/4.0/ c) (i) Open Access

\section{Abstract}

The objective of this study was to conduct a nation-wide survey to investigate the state of: 1) the prevalence of psychological preparation of children undergoing surgery; and 2) the awareness of psychological preparation of children by medical professionals (physicians and nurses). We also aimed to identify the issues that need to be addressed next. A total of 178 physicians and 291 nurses working in hospitals where children undergo surgeries participated in this study. Anonymous self-administered questionnaire survey. Physicians and nurses in Japan are aware of the need to provide age-appropriate psychological preparation for children undergoing medical procedures. In current practice, however, our study revealed that surgical orientations are given solely to parents in the absence of the child in approximately $30 \%$ of cases. While approximately $60 \%$ of respondents felt that the uses of "children's picture books and booklets" are good methods for delivering explanations to children, only about $20 \%$ of respondents were implementing psychological preparation specific to each age group, and half of the respondents were providing verbal explanations alone. Meanwhile, $77 \%$ responded that it is "time-consuming" and $48 \%$ said, "on the contrary, it may heighten their anxiety". Also $34.3 \%$ said that they "do not know how to explain to a child" and $54.8 \%$ of these medical professionals worked in mixed wards. We observed a gap between ideal requirements and current practices. We found that it is essential to: 1) organize training sessions for knowledge acquisition; 2) consciously strive to be informed of the actual post-surgery conditions and outcomes of the children; and 3) acquire physical and financial support.

\section{Keywords}

The Awareness, Psychological Preparation, Children Undergoing Surgery, Physicians and Nurses in Japan 


\section{Introduction}

The need for psychological preparation to minimize the emotional stress of children undergoing medical procedures has been advocated in the West since the 1930s [1]. In the 1940s and 50s, along with allowing parents unlimited visitation, pediatric nursing practice began to consider the emotional impact of an illness and hospital stay on a child. Psychological preparation programs that incorporated pre-admission hospital tours, booklets and children's picture books, puppets and drawing therapy were developed [2]. Around the 1970s, this concept was adopted in the field of nursing in Western countries. In 1994, triggered by the ratification of the Convention of the Rights of the Child in Japan, books and journals introduced psychological preparation as one of the ways to protect the rights of a child in the medical setting. In 1998, Kiuchi et al. introduced "preparation" as a word that points to a child's informed consent, which had been used in Sweden as part of play therapy. In 1999, the Japanese Nursing Association included in its Standards of Practice for Pediatric Nursing the need to: 1) timely explain testing, treatment, medical condition and procedures to the child and the child's guardians, and 2) strive to obtain consent, approval and understanding from them. The Japanese Nursing Association proposed the importance of using simple, developmentally appropriate language and pictures [3]. Since then, psychological preparation has gradually been introduced into practice in hospital wards and in research. There were 334 literature citations in the Japan Medical Abstracts Society website in the 10 years between 1999 and 2009. A rapid increase was observed after 2002, when 255 citations were found.

Since 2002, we have been investigating the status of the practice of psychological preparation and prevalence in the field [4]. In the present study, we added new items to our previous survey questions and conducted a nation-wide survey to investigate the current status and bring to light the relevant issues. This study will report the findings of an awareness survey of medical professionals working at hospitals where they are involved with children's surgeries.

\subsection{Definition of Terminology}

In this study, "psychological preparation” refers to the mental and emotional preparedness of a child undergoing a medical procedure. This study focused on respecting the "right of a child to know"; therefore, psychological preparation was investigated from the perspective of "providing an explanation to the child".

\subsection{Study Objective}

The objective of this study was to conduct a nation-wide survey to investigate the state of: 1) the prevalence of psychological preparation of children undergoing surgery; and 2) the awareness of psychological preparation of children by medical professionals (physicians and nurses). We also aimed to identify the issues that need to be addressed next.

\section{Methods}

\subsection{Participants}

A total of 178 physicians and 291 nurses working in hospitals where children undergo surgeries participated in this study.

\subsection{Survey Method}

Anonymous self-administered questionnaire survey

Prior to conducting the survey, requests were sent out to 2400 hospitals with pediatric practices. Questionnaires were delivered to those hospitals that indicated their willingness to cooperate. Completed forms were collected through either the placement method or by return mail.

\subsection{Scope of the Survey}

Medical professionals (physicians and nurses) participated by providing their opinions about the "psychological preparation of children undergoing surgery". The main questions on the survey sought to investigate: 1 ) the need to provide explanations to children about their surgeries and current practices; 2) actual details of explanations that are currently given and suggestions on areas where briefing and support is further needed; 3) actual methods 
of presenting the information and opinions on successful delivery methods; and 4) opinions and personal experiences on briefing children undergoing surgery and how to assist with their psychological preparation.

\subsection{Method of Analysis}

Numerical data was tabulated using Microsoft Excel. Statistical analysis was conducted using the $x^{2}$ test in SPSS software version 19 (IBM, Chicago, IL). Data were rounded to two decimal points.

\subsection{Ethical Considerations}

A request to the participants was attached to the questionnaire in the form of a letter from the Hospital Director. Participation in the study was on a voluntary basis. Consent was assumed upon return of the completed questionnaire. To ensure anonymity, there was no place to write facility or personal names on the questionnaire. To prevent data leakage, data were stored on a computer secured by a password and were only used for purposes of this study.

\section{Results}

\subsection{Basic Attributes of Participants (Table 1)}

A total of 236 medical professionals (50.7\% response rate) working at hospitals where surgeries on children are

\section{Table 1. Background of participants.}

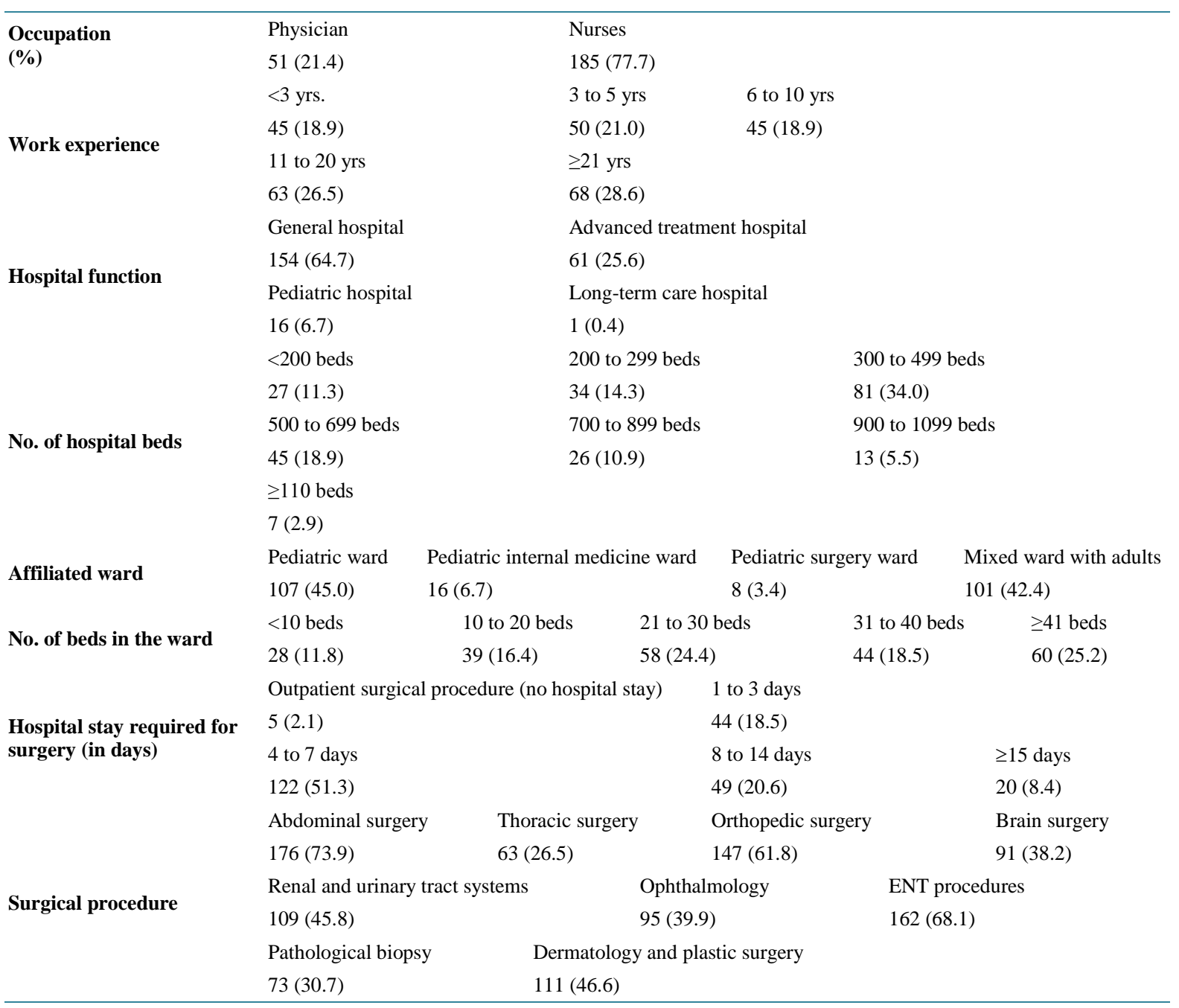


performed responded to the questionnaire. The breakdown was as follows: 51 physicians (28.7\% response rate) and 185 nurses (63.6\% response rate). The number of beds in the hospitals where the participants worked was as follows: $<300$ bed hospital (25.6\%), between 300 and 500 bed hospital (34.0\%), and $\geq 500$ bed hospital (38.2\%). As for their affiliation, $55.1 \%$ of the respondents worked in hospital wards exclusively for children and $42.4 \%$ worked in mixed wards alongside adult patients. Hospital stay required for postoperative recovery, from the most common type of surgery to the least common, was "between 4 to 7 days" (51.3\%), "8 to 14 days" (20.6\%) and "1 to 3 days" (18.5\%).

\subsection{The Need to Explain Surgical Procedures to Children and Current Practices}

With regard to explaining surgical procedures to children, 85.3\% of participants "strongly agree" that "depending on the child's age, explanation of surgical procedures to the child is necessary". Combined with the $8.4 \%$ of participants who said, "slightly agree", more than $90 \%$ of participants expressed the need. In current practice, 49.6\% replied that they "often" provide "explanations depending on the child's age". Similarly, $26.1 \%$ said that explanations are provided "most of the time". Out of the36 participants (15.1\%) who responded "sometimes" and "none at all" to the question whether in current practice "explanations are provided depending on the child's age", all participants said that they either "strongly agree" or "slightly agree" to the question "depending on the child's age, explanation of surgical procedures to the child is necessary" (Figure 1).

A total of $14.2 \%$ responded that they "strongly agree" and "slightly agree" that it is "sufficient to brief the parents during surgical orientation and children do not have to be present". Combined with those who responded, "slightly disagree" and "strongly disagree" the total was 77.7\% (Figure 2). Out of these respondents, 23 participants (53.5\%) said that they are currently "conducting surgical orientation for parents with children". As for those who are currently "conducting surgical orientation for parents without children”, $13.0 \%$ responded "often” and $16.4 \%$ said "most of the time", which indicated that approximately $30 \%$ are engaged in this practice. In this $30 \%$ of respondents, $66.7 \%$ replied that they "slightly disagree" and "strongly disagree" that it is "sufficient to brief parents during surgical orientation and children do not have to be present" $(\mathrm{p}<0.01)$ and they all responded that "depending on the child's age, explanation of surgical procedure to the child is necessary" (Figure 3).

\subsection{The Ideal Method for Explaining to Children and Current Practices}

As for the ideal method for explaining to children, approximately $60 \%$ of the participants responded that for each age group, "dolls" and "children's picture books and booklets" should be used, and 10\% to 30\% responded that "only verbally" was ideal. In current practice, approximately $40 \%$ of the participants explain "only verbally" and about 25\% use "children's picture books and booklets" (Figure 4).

\subsection{Awareness of Psychological Preparation of Children}

Over $90 \%$ of the participants "strongly agree" and "slightly agree” that psychological preparation both "nurtures a trusting relationship with the child" and "nurtures a trusting relationship with the family". In addition, $80 \%$ of participants responded that it is "necessary for the future emotional development of the child" and that they "understand that this means 'to explain to the child before hand'”. Meanwhile, 77\% responded that it is "timeconsuming" and $48 \%$ said, "on the contrary, it may heighten their anxiety". Also $34.3 \%$ said that they "do not know how to explain to a child" and $54.8 \%$ of these medical professionals worked in mixed wards.

\subsection{Requirements for the Provision of Psychological Preparation of Children}

When the participants were asked what was required for psychological preparation, over $90 \%$ responded that they "strongly agree" and "slightly agree" that the following is required: "information on the significance and effects of psychological preparation"; "training sessions on how to implement psychological preparation"; "collaborative relationships with other members involved in preparation process (i.e. doctors and nurses)"; "providing not only pre-surgery explanation, but also to be informed of the child's actual post-surgery conditions and outcome"; "reorganizing workload to free up time"; "understanding and cooperation from superior doctors and nurses"; "one’s motivation and drive to implement psychological preparation"; and "funding to purchase materials for the explanation". 


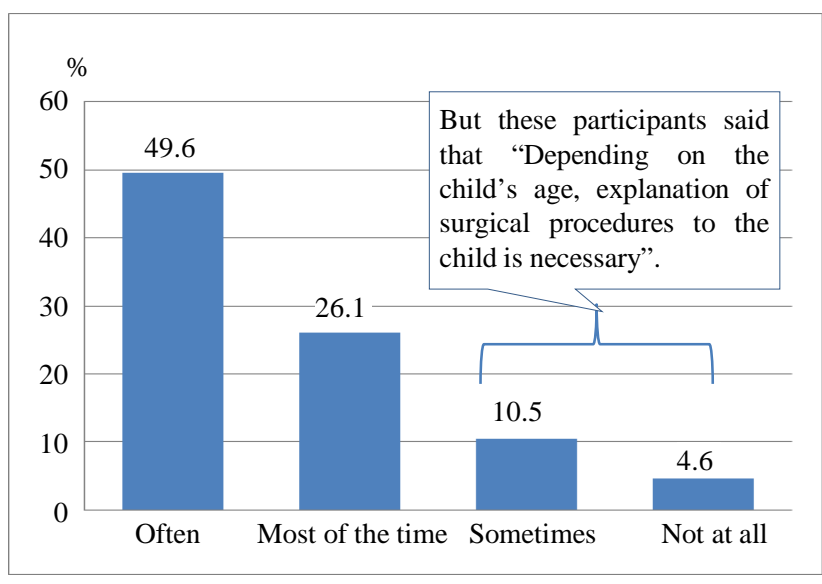

Figure 1. Explanations are provided depending on the child's age.

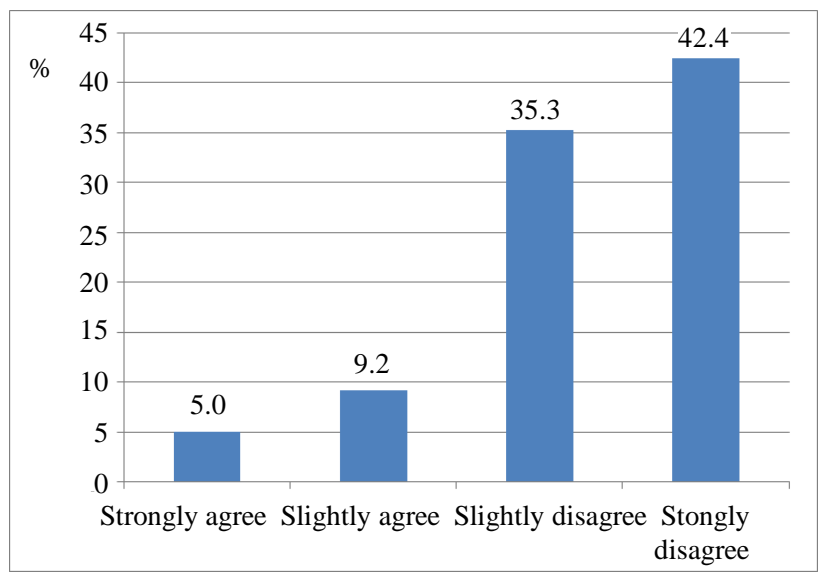

Figure 2. Sufficient to brief parents during surgical orientation and children do not have to present.

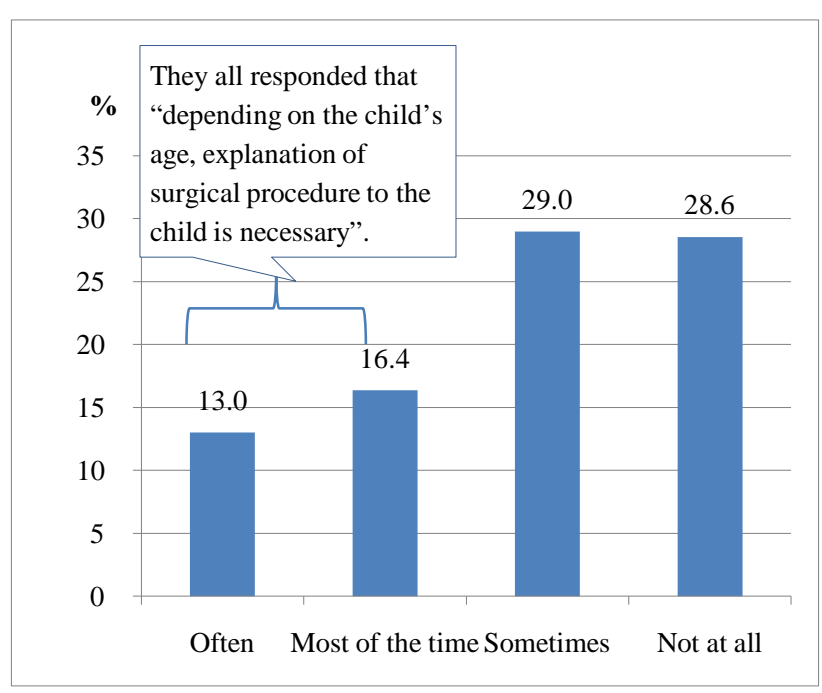

Figure 3. Conduct surgical orientation for parents without children. 


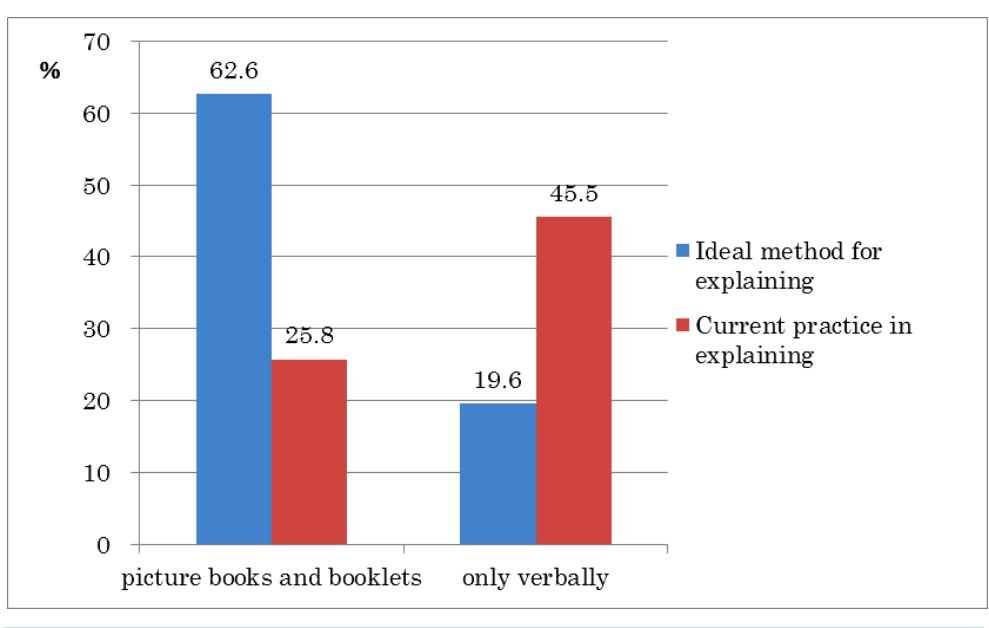

Figure 4. Awareness and current practice in explanation process.

\subsection{Open-Ended Responses (Table 2)}

The responses to the open-ended questions received from the doctors and nurses were divided into 10 categories depending on the content of their replies and presented within [brackets]. Within each category, some representative responses are quoted directly, using quotation marks.

In the [implementation by nurses] category, a participant responded that "surgical nurses are responsible for providing the explanation". Participants noted that "dolls are used", "a ward mascot was created" and "used praise" as [methods of explanation and preparation]. As for [considerations for implementing psychological preparation], they suggested that it is "important to have a good time with the child" and to "build a rapport with the nurse". Whether [psychological preparation of the child is necessary], a participant said that it is "not limited to surgical procedures". As for the [effectiveness of explaining to children], a respondent said that "awareness of the importance of child preparation is raised when psychological preparation is implemented". As a [positive reaction of children and their families], a participant responded that he/she was "able to build a trusting relationship with the child's family". However, as a [difficulty in post-implementation evaluation] a participant raised the point of "evaluations being difficult as the surgery only required a short hospital stay". Also, respondents listed "busy schedule", "time-consuming", and "short hospital stay" as reasons for [not practicing psychological preparation]. For those who [do not know], they responded that they "did not know how to proceed". As for [requirements for dissemination of the practice], respondents expressed "interest in opportunities to learn" and "interest in finding out approaches of other hospitals".

Before you begin to format your paper, first write and save the content as a separate text file. Keep your text and graphic files separate until after the text has been formatted and styled. Do not use hard tabs, and limit use of hard returns to only one return at the end of a paragraph. Do not add any kind of pagination anywhere in the paper. Do not number text heads- the template will do that for you.

Finally, complete content and organizational editing before formatting. Please take note of the following items when proofreading spelling and grammar:

\section{Discussion}

\subsection{The Need to Explain Surgical Procedures to Children and Current Practices}

Over $90 \%$ of participants responded either "strongly agree" or "slightly agree" that surgical explanation for children is needed "depending on the age of the child". Ebina et al. (2004) found that $10 \%$ of physicians and $30 \%$ of nurses felt the need to explain surgical procedures to children between the ages of 3 and 5 [4]. Similarly, slightly less than $40 \%$ and $70 \%$ of physicians and nurses, respectively, felt that explanations were needed for children between the ages of 6 and 8. For children between the ages of 13 and 16, 70\% of physicians and approximately $90 \%$ of nurses responded that explanations were needed. Since this study did not investigate the need of explanation by proportion for different age groups, their perception for each age group was not identified. However, their awareness has been raised. While approximately $30 \%$ of all the participants responded that 
Table 2. Responses to the open-ended questions.

\begin{tabular}{|c|c|}
\hline Category & Subcategory \\
\hline \multirow{2}{*}{ Implementation by nurses } & Ensured cooperation from surgical nurses \\
\hline & Surgical nurses are responsible for providing the explanation \\
\hline \multirow{5}{*}{$\begin{array}{l}\text { Methods of explanation and } \\
\text { preparation }\end{array}$} & Dolls are used \\
\hline & A “ward mascot” was created \\
\hline & Use a self-produced information video \\
\hline & Produce a booklet, use picture books for explaining \\
\hline & Use praise \\
\hline \multirow{3}{*}{$\begin{array}{l}\text { Considerations for implementing } \\
\text { psychological preparation }\end{array}$} & Important to follow the lead of the child \\
\hline & Important to adjust to the child's level of understanding \\
\hline & Build rapport with the nurse \\
\hline \multirow{3}{*}{$\begin{array}{l}\text { Psychological preparation of the } \\
\text { child is necessary }\end{array}$} & Psychological preparation of the child is important \\
\hline & Not limited to surgical procedures \\
\hline & Implemented when anxiety is severe \\
\hline \multirow{2}{*}{$\begin{array}{l}\text { Effectiveness of explaining to } \\
\text { children }\end{array}$} & Effective when implemented before and after surgical procedure \\
\hline & $\begin{array}{l}\text { Awareness of the importance of child preparation is raised, when psychological preparation is } \\
\text { implemented }\end{array}$ \\
\hline \multirow{5}{*}{$\begin{array}{l}\text { Positive reaction of children and their } \\
\text { families }\end{array}$} & Acceptance in infants is favorable \\
\hline & Able to build a trusting relationship with the child's family \\
\hline & Measurement was possible by allowing them to touch the blood pressure gauge \\
\hline & Proudly announced termination of IV drip to pediatric roommates \\
\hline & Able to see the child striving hard \\
\hline \multirow{2}{*}{$\begin{array}{l}\text { Difficulty in post-implementation } \\
\text { evaluation }\end{array}$} & Evaluation was difficult as the surgery only required a short hospital stay \\
\hline & Not evaluated \\
\hline \multirow{2}{*}{ Do not know } & Do not know how to proceed \\
\hline & Do not know as I am a physician in Pediatric Internal Medicine \\
\hline \multirow{7}{*}{$\begin{array}{l}\text { Not practicing psychological } \\
\text { preparation }\end{array}$} & Busy schedule and time consuming \\
\hline & The challenge is finding a way to implement it with all the children \\
\hline & Due to a short hospital stay \\
\hline & Located in a mixed ward alongside adults \\
\hline & It was not a major procedure that required explanation \\
\hline & Unable to obtain the understanding of superiors \\
\hline & Explanation was parent-centered \\
\hline \multirow{6}{*}{$\begin{array}{l}\text { Requirements for dissemination of } \\
\text { the practice }\end{array}$} & Interest in finding out approach of other hospitals \\
\hline & Interest in opportunities to learn \\
\hline & Not useful unless data is compiled \\
\hline & Learn ways to disseminate the practice \\
\hline & Sharing of information with other professions \\
\hline & Convenient if picture books and other explanation tools are commercially available \\
\hline
\end{tabular}

they "conduct surgical orientation without children" in their current practice, $60 \%$ of these respondents do not agree with "conducting surgical orientation without children" and all participants agree that "depending on the child's age, explanation of surgical procedures to the child is necessary". In other words, there was a gap between awareness and current practice.

As noted above, participants know and are aware that age-appropriate explanations are needed for children; however, the study revealed that in real life, about $30 \%$ of surgical orientations are conducted for parents without children. Work is needed on raising awareness to respect and assent to the right of a child, as recommended by the American Academy of Pediatrics [5]. 


\subsection{Recommendations on Methods for Explaining Surgical Procedures to Children and Current Practices}

As a good method for explaining to children, approximately $60 \%$ of the participants mentioned the use of "children's picture books and booklets" for each of the age groups. In contrast, however, only approximately $20 \%$ have used these in practice for each of the age groups. In other words, there was a difference between recommendations and current practices.

In the study, $10 \%$ of participants responded that "only verbally" was an ideal method for explaining to children between the ages of 3 and 5. Likewise, 20\% and 30\% responded that this was an ideal method for children between the ages of 6 and 8 , and 9 and 12, respectively. In current practice, however, fewer than $40 \%$ and $50 \%$ of participants use verbal explanations for 3 to 5 year olds and 6 to 8 year olds, respectively, and over $50 \%$ use verbal means for 9 to 12 year olds. In other words, this is the most common method for providing explanations.

In 1981, Mehrabian stated that the determining factor of judging what a person is feeling about you is $50 \%$ or more dependent on facial expression and 38\% through one's tone of voice [6]. The meaning of spoken words has an effect of only 7\%. In the case of "only verbally", which is the most common method of explanation, expressive facial expressions and use of animated voices could alleviate fear as well as help the child feel the caring thoughts of the medical professionals. Visual tools, such as children's picture books and dolls, can be used to augment facial expression and tone of voice in delivering the information and can also be a way to build a trusting relationship with the medical professional. In addition to communicating words, these visual tools need to be introduced to effectively relieve anxieties of children.

\subsection{Issues and Measures for Providing Psychological Preparation of Children}

The fact that $80 \%$ of participants "understand that psychological preparation means to 'explain to the child beforehand"”, the basis of psychological preparation is rooted in "providing and communicating the information". The reason is to promote the future emotional development of children and ultimately to nurture the trusting relationship of the child and family with the medical staff. However, the negative element of psychological preparation being "time-consuming" needs to be resolved by reorganization of workload. Not simply time-consuming explanations but incorporating "distractions" such as music, TV and breathing methods could also be effective, as suggested by Koller et al. (2012) [7]. Regarding the opinion that information makes children anxious, Fincher et al. (2012) reported that while photographs, demonstrations of equipment using role modeling, and visitation tours were not effective in minimizing anxiety in children, these methods did assist in lessening anxiety in parents and in decreasing the pain experienced by the child after the operation [8]. According to Breiner, S. (2009), experience of an invasive medical procedure can leave a negative impression on the psychological well-being of the child in the months and years after the procedure; and techniques and supportive measures for psychological preparation that promote coping and follow-up are effective in minimizing the negative effects [9]. There is a need to "provide not only pre-surgery explanations" but to consciously strive to follow up and "be informed of the child's actual post-surgery conditions and outcome". At the same time, it is essential to derive motivation through evaluation of nursing practices. As there are many cases of short-stay hospitalization, collaboration with outpatient nursing staff is essential. Out of those who responded that they did not know how to provide psychological preparation, there were $54.8 \%$ medical professionals who worked in mixed wards. Regarding this issue, we identified the need to provide educational opportunities for nurses who work primarily with adult patients in mixed wards (adult and pediatric practices). Training sessions for teaching the significance, effects, and delivery methods of psychological preparation will be needed. Financial support as well as physical support from colleagues and superior physicians and nurses to seek assistance and understanding is important. However, as noted by Perry et al. (2012), in order to disseminate the practice of psychological preparation, further investigation is needed to assess the effectiveness and economic effects [10].

\section{Conclusions}

Physicians and nurses in Japan are aware of the need to provide age-appropriate psychological preparation for children undergoing medical procedures. In current practice, however, our study revealed that surgical orientations are given solely to parents in the absence of the child in approximately $30 \%$ of cases. While approximately $60 \%$ of respondents felt that the uses of "children's picture books and booklets" are good methods for delivering 
explanations to children, only about $20 \%$ of respondents were implementing psychological preparation specific to each age group, and half of the respondents were providing verbal explanations alone. We observed a gap between ideal requirements and current practices. We found that it is essential to: 1) organize training sessions for knowledge acquisition; 2) consciously strive to be informed of the actual post-surgery conditions and outcomes of the children; and 3) acquire physical and financial support.

\section{Acknowledgements}

I would like to express my sincere appreciation to all the hospital officials and personnel for supporting this study. This study was supported by Grants-in-Aid for Scientific Research (B) "Development of a preparation model for children who are undergoing medical procedures and surgeries and development of educational materials" in Japan.

\section{References}

[1] Beverly, B.I. (1935) The Effect of Illness upon Emotional Development. The Journal of Pediatrics, 8, 533-543. http://dx.doi.org/10.1016/S0022-3476(36)80152-8

[2] Bar-Mor, G. (1997) Preparation of Children for Surgery and Invasive Procedures: Milestones on the Way to Success, Journal of Pediatric Nursing, 12, 252-255. http://dx.doi.org/10.1016/S0882-5963(97)80010-3

[3] Matsumori, N. and Isfort M. (2013) Psychological Preparation Practices for Children Undergoing Medical Procedures in Japan and Germany. Open Journal of Nursing, 3, 281-286. http://dx.doi.org/10.4236/ojn.2013.32038

[4] Ebina, M. (2004) The Practical Application and Evaluation of a Care Model for Information and Reassuring Children Who Are to Undergo Medical Examination and Procedures. The Report of the Ministry of Health, Labor and Welfare Scientific Research in Japanese, 89-130.

[5] Unguru Y.T. (2011) Informed Consent and Assent in Pediatrics. In: Adam, M.B., Diekema, D.S. and Mercurio, M.R. Eds., Academy of Pediatrics Bioethics Resident Curriculum: Case-Based Teaching Guides, The American Academy of Pediatrics Committee on Bioethics and Section on Bioethics, Elk Grove Village, 24-31.

[6] Mehrabian, A. (1981) Silent Messages: Implicit Communication of Emotions and Attitudes. 2nd Edition, Wadsworth, Belmont.

[7] Koller, D. and Goldman, R. (2012) Distraction Techniques for Children Undergoing Procedures: A Critical Review of Pediatric Research. Journal of Pediatric Nursing, 27, 652-681. http://dx.doi.org/10.1016/j.pedn.2011.08.001

[8] Fincher, W., Shaw, J. and Ramelet, A. (2012) The Effectiveness of a Standardized Preoperative Preparation in Reducing Child and Parent Anxiety: A Single-Blind Randomized Controlled Trial. Journal of Clinical Nursing, 21, 946-955. http://dx.doi.org/10.1111/j.1365-2702.2011.03973.x

[9] Breiner, S. (2009) Preparation of the Pediatric Patient for Invasive Procedures. Journal of Infusion Nursing: The Official Publication of the Infusion Nurses Society, 32, 252-256. http://dx.doi.org/10.1097/NAN.0b013e3181b42d482

[10] Perry, J.N., Hooper, V.D. and Masiongale, J. (2012) Reduction of Preoperative Anxiety in Pediatric Surgery Patients Using Age-Appropriate Teaching Interventions. Journal of Peri Anesthesia Nursing, 27, 69-81. http://dx.doi.org/10.1016/j.jopan.2012.01.003 


\section{Appendix}

Questionary survey to relate to psychological preparation for children undergoing surgery (for time required 15)

Thank you for your cooperation to answer this questionnaire.

Please check the number about each question or fill out the blanks, and please reply it.

\section{Please answer about your background. Please mark an applicable term or number.}

$<$ Working place $>$

$$
\begin{aligned}
& \square \text { Hokkaido } \quad \square \text { North of Japan } \quad \square \text { Kanto } \quad \square \text { Hokuriku } \quad \square \text { Middle of Japan } \\
& \square \text { Kinki } \square \text { Shikoku Iland } \square \text { Chugoku } \square \text { Kyushu } \square \text { Okinawa }
\end{aligned}
$$

$<$ Hospital function $>$

$$
\begin{aligned}
& \square \text { General hospital } \quad \square \text { Advanced treatment hospital } \quad \square \text { Pediatric hospital } \\
& \square \text { Long-term care hospital } \quad \square \text { Others ( }
\end{aligned}
$$

$<$ The number of hospital beds $>$

$$
\begin{aligned}
& \square<200 \text { beds } \quad \square 200-300 \text { beds } \quad \square 300-500 \text { beds } \quad \square 500-700 \text { beds } \\
& \square 700 \text { - } 900 \text { beds } \quad \square 900-1100 \text { beds } \quad \square>1100 \text { beds }
\end{aligned}
$$

$<$ Affiliated ward $>$

$\square$ Pediatric department (medical and surgical department) $\quad \square$ Medical department

$\square$ Surgical department $\quad \square$ Mixed ward with the adult and child

$<$ Number of beds in the ward $>$

$$
\square<10 \text { beds } \quad \square 10-20 \text { beds } \quad \square 21-30 \text { beds } \square 31-40 \text { beds } \square>41 \text { beds }
$$

$<$ Occupation $>$

$$
\square \text { Doctor } \quad \square \text { Nurse }
$$

$<$ your position $>$

\begin{tabular}{|c|c|c|}
\hline $\begin{array}{l}\square \text { Abdominal surgery } \\
\square \text { Renal and urinary tract systems } \\
\square \text { Pathological biopsy }\end{array}$ & $\begin{array}{c}\square \text { Thoracic surgery } \\
\square \text { Ophthalmology } \\
\square \text { Dermatology and pl }\end{array}$ & $\begin{array}{l}\square \text { Orthopedic surgery } \\
\square \text { ENT procedures } \\
\text { ic surgery }\end{array}$ \\
\hline
\end{tabular}

$\square$ Mayor of divisional commander, director, ward $\quad \square$ Chief class $\quad \square$ Staff and others (

$<$ Work Experience $>$

$$
\square<3 \mathrm{yrs} \quad \square 3 \text { to } 5 \mathrm{yrs} \quad \square 6 \text { to } 10 \mathrm{yrs} \quad \square 11 \text { to } 20 \mathrm{yrs} \quad \square>21 \mathrm{yrs}
$$

$<$ Hospital stay required for surgery (in days) $>$

$$
\begin{aligned}
& \square \text { Outpatient surgical procedure (no hospital stay) } \quad \square 1 \text { to } 3 \text { days } \quad \square 4 \text { to } 7 \text { days } \quad \square 8 \text { to } 14 \text { days } \\
& \square>15 \text { days }
\end{aligned}
$$

$<$ Surgical procedure $>$ 
Please answer about the need to explain surgical procedures to children and current practices.

\begin{tabular}{|ll|l|}
\hline $\begin{array}{lll}\text { (1) } \text { Strongly agree } & \text { (2) Slightly agree } & \text { (4) Strongly disagree }\end{array}$ & \begin{tabular}{|ll} 
(1) Often & (2) Most of the time \\
(3) Sometimes & (4) Not at all
\end{tabular} \\
\hline
\end{tabular}

\begin{tabular}{|c|c|c|c|c|c|c|c|c|c|}
\hline \multicolumn{5}{|c|}{ The need to explain surgical procedures to children } & \multicolumn{5}{|l|}{ The current practices } \\
\hline $\begin{array}{l}\text { Depending on the child's age, } \\
\text { explanation of surgical procedures to the } \\
\text { child is necessary }\end{array}$ & (1) & (2) & (3) & (4) & $\begin{array}{r}\text { Explanations are provided depending on the } \\
\text { child's age }\end{array}$ & (1) & (2) & (3) & (4) \\
\hline $\begin{array}{l}\text { Depending on the child's disease, } \\
\text { explanation of surgical procedures to the } \\
\text { child is necessary }\end{array}$ & (1) & (2) & (3) & (4) & $\begin{array}{r}\text { Explanations are provided depending on the } \\
\text { child's disease }\end{array}$ & (1) & (2) & (3) & (4) \\
\hline $\begin{array}{l}\text { Depending on the contents of the } \\
\text { explanation, explanation of surgical } \\
\text { procedures to the child is necessary }\end{array}$ & (1) & (2) & (3) & (4) & $\begin{array}{l}\text { Explanations are provided depending on the } \\
\text { contents of the explanation }\end{array}$ & (1) & (2) & (3) & (4) \\
\hline $\begin{array}{r}\text { When parent is absent, explanation of } \\
\text { surgical procedures to the child is } \\
\text { necessary }\end{array}$ & (1) & (2) & (3) & (4) & $\begin{array}{r}\text { When parent is absent, explanations are } \\
\text { provided for children }\end{array}$ & (1) & (2) & (3) & (4) \\
\hline $\begin{array}{r}\text { Sufficient to brief parents during } \\
\text { surgical orientation and children have to } \\
\text { present }\end{array}$ & (1) & (2) & (3) & (4) & $\begin{array}{r}\text { Conduct surgical orientation for parents with } \\
\text { children }\end{array}$ & (1) & (2) & (3) & (4) \\
\hline $\begin{array}{r}\text { Sufficient to brief parents during } \\
\text { surgical orientation and children do not } \\
\text { have to present }\end{array}$ & (1) & (2) & (3) & (4) & $\begin{array}{r}\text { Conduct surgical orientation for parents } \\
\text { without children }\end{array}$ & (1) & (2) & (3) & (4) \\
\hline
\end{tabular}

What is the ideal method for explaining to children and current practices?

\begin{tabular}{|c|c|c|c|c|c|c|}
\hline & \multicolumn{3}{|c|}{ The ideal method for explaining to children } & \multicolumn{3}{|c|}{ Current practices } \\
\hline & 3 to $5 \mathrm{yrs}$ & 6 to $8 \mathrm{yrs}$ & 9 to $12 \mathrm{yrs}$ & 3 to $5 \mathrm{yrs}$ & 6 to $8 \mathrm{yrs}$ & 9 to $12 \mathrm{yrs}$ \\
\hline \multicolumn{7}{|c|}{ Only verbally } \\
\hline \multicolumn{7}{|c|}{ A picture card } \\
\hline \multicolumn{7}{|c|}{$\begin{array}{l}\text { Children's picture } \\
\text { books and booklets }\end{array}$} \\
\hline \multicolumn{7}{|c|}{ Doll } \\
\hline \multicolumn{7}{|c|}{ Photograph } \\
\hline \multicolumn{7}{|c|}{ Personal computer } \\
\hline \multicolumn{7}{|c|}{ Video } \\
\hline \multicolumn{7}{|c|}{ Drawing } \\
\hline \multicolumn{7}{|c|}{ Medical model } \\
\hline \multicolumn{7}{|c|}{$\begin{array}{r}\text { Visiting of surgical } \\
\text { staff }\end{array}$} \\
\hline \multicolumn{7}{|c|}{ Game } \\
\hline \multicolumn{7}{|c|}{ Clinical pass } \\
\hline Others ( & & & & & & \\
\hline
\end{tabular}


How about awareness of psychological preparation of children?

\begin{tabular}{|c|c|c|c|c|}
\hline \multicolumn{5}{|c|}{ (1) Strongly agree (2) Slightly agree (3) Slightly disagree (4) Strongly disagree } \\
\hline Nurtures a trusting relationship with the child & (1) & (2) & (3) & (4) \\
\hline Nurtures a trusting relationship with the family & (1) & (2) & (3) & (4) \\
\hline Necessary for the future emotional development of the child & (1) & (2) & (3) & (4) \\
\hline Interested in putting it into practice myself & (1) & (2) & (3) & (4) \\
\hline Understand that this means to explain to the child "before hand" & (1) & (2) & (3) & (4) \\
\hline Time consuming & (1) & (2) & (3) & (4) \\
\hline Seems difficult & (1) & (2) & (3) & (4) \\
\hline Priority is with other procedures and measures & (1) & (2) & (3) & (4) \\
\hline Do not know how to explain to a child & (1) & (2) & (3) & (4) \\
\hline Do not understand the difference with existing surgical orientation & (1) & (2) & (3) & (4) \\
\hline On the contrary, it may heighten the child's anxiety & (1) & (2) & (3) & (4) \\
\hline Do not understand the significance and effects of explaining to a child & (1) & (2) & (3) & (4) \\
\hline
\end{tabular}

How about requirements for the provision of psychological preparation of children?

\begin{tabular}{|c|c|c|c|c|}
\hline (1) Strongly agree (2) Slightly agree (3 & Slightly dis & ree & (4) Strc & Jly disagree \\
\hline Information on the significance and effects of psychological preparation & (1) & (2) & (3) & (4) \\
\hline Training sessions on how to implement psychological preparation & (1) & (2) & (3) & (4) \\
\hline $\begin{array}{l}\text { Collaborative relationships with other members involved in preparation process } \\
\text { (i.e., doctors and nurses) }\end{array}$ & (1) & (2) & (3) & (4) \\
\hline $\begin{array}{l}\text { Providing not only pre-surgery explanation, but also to be informed of the child's } \\
\text { actual post-surgery conditions and outcome }\end{array}$ & (1) & (2) & (3) & (4) \\
\hline Reorganizing workload to free up time & (1) & (2) & (3) & (4) \\
\hline Understanding and cooperation from superior doctors and nurses & (1) & (2) & (3) & (4) \\
\hline One's motivation and drive to implement psychological preparation & (1) & (2) & (3) & (4) \\
\hline Funding to purchase materials for the explanation & (1) & (2) & (3) & (4) \\
\hline Implementation should reflect on the evaluation of nursing practice & (1) & (2) & (3) & (4) \\
\hline Collaboration with other health professionals & (1) & (2) & (3) & (4) \\
\hline $\begin{array}{l}\text { Economic benefit from implementation such as collecting National Health } \\
\text { Insurance (NIH) points }\end{array}$ & (1) & (2) & (3) & (4) \\
\hline Increase number of nurses & (1) & (2) & (3) & (4) \\
\hline Wait until the child is mentally and emotionally prepared & (1) & (2) & (3) & (4) \\
\hline Patients recover faster by receiving psychological preparation & (1) & (2) & (3) & (4) \\
\hline Increase number of physicians & (1) & (2) & (3) & (4) \\
\hline Reduction of medical cost by implementing psychological preparation & (1) & (2) & (3) & (4) \\
\hline \multicolumn{5}{|l|}{ Please write about psychological preparation. (Open-Ended Responses) } \\
\hline
\end{tabular}

